\title{
Prognostic factors for survival in multiple sclerosis: a longitudinal, population based study in Møre and Romsdal, Norway
}

\author{
R Midgard, G Albrektsen, T Riise, G Kvåle, H Nyland
}

\begin{abstract}
A longitudinal, population based study of life expectancy in multiple sclerosis was performed in the county of Møre and Romsdal, Norway during the period 1950-84. A total of 251 patients with multiple sclerosis (110 men, 141 women, mean age at onset of disease 33.6 years) were included. The mean follow up time was $18 \cdot 1$ years. At the end of the study period 70 patients had died. Fifty four $(77 \cdot 1 \%)$ of these had multiple sclerosis as the underlying or contributing cause of death on the death certificates. Young age at onset, initial remitting clinical course, and the presence of sensory symptoms at onset were significantly associated with longer survival.
\end{abstract}

(F Neurol Neurosurg Psychiatry 1995;58:417-421)

Keywords: multiple sclerosis; life expectancy; prognosis

Multiple sclerosis is an inflammatory, demyelinating disease of the CNS that shows an exceptionally variable clinical course and prognosis. ${ }^{1}$ Many studies have dealt with survival and factors influencing the duration of disease in multiple sclerosis. ${ }^{2-6}$ Age at onset, sex, and initial symptoms have been the most often studied prognostic determinants. These variables are interdependent. Most authors find a worse prognosis in patients who are relatively old at onset. ${ }^{7-9}$ Optic neuritis as the initial clinical manifestation seems to be favourable, ${ }^{7910}$ whereas pyramidal and cerebellar clinical signs, and the presence of multiple symptoms give a poor prognosis. ${ }^{781011}$ Sensory symptoms have a favourable influence on the prognosis compared with motor symptoms alone. ${ }^{7} \mathrm{~A}$ reduced life expectancy in patients with multiple sclerosis compared with the normal population was recently found by Poser et al, ${ }^{12}$ whereas the differential survival by sex and age seemed to reflect the expected survival by sex and age themselves. Based on two epidemiological studies in Norway, Riise et $a l^{13}$ found that older age at onset, progressive course of disease initially, and vertigo as the initial clinical manifestation indicated an unfavourable prognosis. In a previous study, we have evaluated the initial clinical variables of age at onset, sex, initial clinical course, and first symptoms as prognostic factors for disability in seven centres in five European countries. ${ }^{14}$

The present study was carried out to deter- mine the potential impact on survival of demographic and clinical factors such as age at onset, sex, initial clinical course, and initial symptoms in population based material from a high risk area of multiple sclerosis in western Norway.

\section{Materials and methods}

Two hundred and fifty one patients with multiple sclerosis, 110 men and 141 women, with onset of multiple sclerosis in the county of Møre and Romsdal in the period 1950-84 met the inclusion criteria. ${ }^{15}$ The patients were classified according to McAlpine's clinical criteria ${ }^{10}$ into groups of definite (142 patients), probable (43 patients), and possible multiple sclerosis (66 patients). The mean age at onset was 33.6 (range $14 \cdot 0-61 \cdot 0$ ) years. The patients were divided into remitting (including remitting progressive) and primary progressive categories based on the initial clinical course of the disease. The disease development was classified as remitting when there was a minimum duration of complete or partial remission of at least six months. The criterion for progressive disease was continuing deterioration without remission, whatever the rate of decline. The manifestations at onset of disease, the time of diagnosis, and the clinical course from initial symptoms to diagnosis were assessed retrospectively. The main initial symptoms were recorded for each patient. Only clinical symptoms and signs appearing during the first month of disease were included on registration. The retrospective assessment of these symptoms and signs was based on the primary clinical records by the local general practitioners and the attending neurologist. These primary records were made close to the onset of disease, and include systematic registration of symptoms, signs, and results of ancillary investigations. Clinical follow up by the attending neurologist was performed once every year or more often depending on clinical activity in the disease. The number of cases with an immediate neurological examination at onset, and the interval between onset and first neurological examination was not recorded. In several cases, however, the interval from onset to diagnosis of disease is equal to the interval from onset until the first clinical examination. The mean interval between onset and diagnosis of disease was 5.7 years. The deceased patients were unknown to us when the assessment of the clinical characteristics was done.

The clinical manifestations were classified 
into categories such as optic neuritis, diplopia, trigeminal neuralgia, facial paresis, vertigo, ataxia, dysarthria, paraesthesiae, motor weakness, bladder dysfunction, and others. Forty three patients were recorded with only one initial clinical manifestation, 83 were recorded with two, 94 with three, 26 with four, and five patients were recorded with five different symptoms and signs. The presence or absence of each symptom was determined for all patients.

The record of clinical course took place retrospectively through scrutiny and reassessment of the files of patients with multiple sclerosis in the Department of Neurology, Molde Hospital. The primary source of patients with multiple sclerosis was the record files (inpatients and outpatients) of the Department of Neurology at Molde County Hospital, the only Neurological Department in the county. In addition, the three other county hospitals, local physicians, the local multiple sclerosis society, the National Insurance Administration, and Statistics Norway (the Registry of Death Causes) served as sources of information. ${ }^{15}$ None of the patients had received immunomodulating drug treatment (for example, azathioprine, cyclophosphamide). Systemic corticosteroids or ACTH had been given during acute exacerbations. Follow up of each patient started at time of onset, which was set to 1 July of the recorded year of onset. By the end of the follow up period, 1 July 1991, 70 patients with multiple sclerosis had died. Mortality ascertainment was performed by combining the clinical material with the national Registry of Death Causes. The death certificates were assessed for the number of cases coded with multiple sclerosis as the underlying (42 patients) and contributing (12 patients) cause of death.

SURVIVAL ANALYSIS

A univariate survival analysis for the different demographic and clinical variables was performed according to the product limit
(Kaplan-Meier) procedure. Due to the low number of deceased patients, we present the $75 \%$ rather than the $50 \%$ (median) survival rate as an indication of prognosis. Tests for differences in survival curves for different categories of variables were performed with Mantel-Cox statistics. ${ }^{16}$ Variables that had a significant effect on survival at the $10 \%$ level in the univariate analysis were further analysed in the multivariate Cox proportional hazard regression model, ${ }^{17}$ to see which variables had independent prognostic importance. The variables were investigated in log minus log plots to assess whether assumptions about linearity and proportionality were met. Hazard ratios were calculated as measures of effect.

Separate survival analyses were performed with all causes of death (total mortality) as endpoint, and with multiple sclerosis as underlying or contributing cause of death (multiple sclerosis specific mortality) only as endpoint. Patients with multiple sclerosis dying of causes other than multiple sclerosis were in these analyses censored at time of death. The statistical analyses were performed by means of BMDP software packages. ${ }^{18}$

\section{Results}

The univariate analyses showed that survival was significantly related to sex, age at onset, and clinical course. The shortest survival was in men, and in patients with high age at onset and a progressive clinical course (table 1). Mortality with multiple sclerosis as underlying and contributing cause of death was not, however, significantly different between men and women, and the relation to age at onset and clinical course were weaker. The prognostic effect of year of onset and the separate diagnostic categories of multiple sclerosis did not reach statistical significance on the $5 \%$ level. Patients with ataxia and patients without paraesthesiae at onset had significantly shorter survival than those without ataxia and with

Table 1 Univariate survival analysis * of multiple sclerosis in Møre and Romsdal, Norway 1950-84

\begin{tabular}{|c|c|c|c|c|c|c|c|}
\hline \multirow[b]{2}{*}{ Variable } & \multirow[b]{2}{*}{ Total No } & \multicolumn{2}{|c|}{ No dead } & \multicolumn{2}{|c|}{$75 \%$ survival $(y)$} & \multicolumn{2}{|c|}{ Pvalue (Mantel-Cox) } \\
\hline & & Total & Multiple sclerosis $\ddagger$ & Total & Multiple sclerosis $\ddagger$ & Total & Multiple sclerosis $\ddagger$ \\
\hline \multicolumn{8}{|l|}{ Sex: } \\
\hline Men & 110 & 41 & 28 & $15 \cdot 5$ & $21 \cdot 3$ & 0.003 & 0.09 \\
\hline Women & 141 & 29 & 26 & $24 \cdot 1$ & $24 \cdot 5$ & & \\
\hline \multicolumn{8}{|l|}{ Age at onset $(y)$ : } \\
\hline$<30$ & 101 & 14 & 13 & $34 \cdot 3$ & $34 \cdot 3$ & $<0.0001$ & 0.002 \\
\hline $30-39$ & 79 & 26 & 22 & $19 \cdot 4$ & $23 \cdot 0$ & & \\
\hline $40-49$ & 41 & 13 & 10 & $17 \cdot 0$ & $19 \cdot 9$ & & \\
\hline$\geqslant 50$ & 30 & 17 & 9 & $12 \cdot 1$ & $18 \cdot 0$ & & \\
\hline \multicolumn{8}{|l|}{ Year of onset: } \\
\hline $1950-9$ & 49 & 31 & 26 & $21 \cdot 3$ & $22 \cdot 6$ & 0.07 & 0.31 \\
\hline $1960-9$ & 59 & 17 & 14 & $23 \cdot 7$ & $24 \cdot 5$ & & \\
\hline $1970-84$ & 143 & 22 & 14 & $16 \cdot 5$ & $18 \cdot 2$ & & \\
\hline \multicolumn{8}{|l|}{ Diagnosis: } \\
\hline definite & 142 & 37 & 36 & $21 \cdot 3$ & $23 \cdot 0$ & 0.48 & 0.55 \\
\hline probable & 43 & 13 & 8 & $16 \cdot 9$ & $22 \cdot 6$ & & \\
\hline possible & 66 & 20 & 10 & $18 \cdot 0$ & $24 \cdot 5$ & & \\
\hline \multicolumn{8}{|l|}{ Clinical course: } \\
\hline $\begin{array}{l}\text { Remitting }+ \\
\text { remitting progressive }\end{array}$ & 214 & 48 & 40 & $22 \cdot 6$ & $23 \cdot 7$ & $0 \cdot 0004$ & 0.05 \\
\hline Primary progressive & 37 & 22 & 14 & $13 \cdot 1$ & $17 \cdot 0$ & & \\
\hline
\end{tabular}

*Including definite, probable, and possible multiple sclerosis.

tAll causes of death.

$\ddagger$ Multiple sclerosis as underlying and contributing cause of death. 
Table 2 Univariate survival analysis* of multiple sclerosis in More and Romsdal, Norway 1950-84 by clinical manifestations at onset

\begin{tabular}{|c|c|c|c|c|c|c|c|}
\hline \multirow[b]{2}{*}{ Manifestation } & \multirow[b]{2}{*}{ Total No } & \multicolumn{2}{|c|}{ No dead } & \multicolumn{2}{|c|}{$75 \%$ survival $(y)$} & \multicolumn{2}{|c|}{ Pvalue (Mantel-Cox) } \\
\hline & & Total $\dagger$ & Multiple sclerosis $\ddagger$ & Totalt & Multiple sclerosis $\ddagger$ & Totalt & Multiple sclerosis $\ddagger$ \\
\hline \multicolumn{8}{|c|}{ Optic neuritis: } \\
\hline $\begin{array}{l}\text { No } \\
\text { Yes }\end{array}$ & $\begin{array}{r}165 \\
86\end{array}$ & $\begin{array}{l}48 \\
22\end{array}$ & $\begin{array}{l}36 \\
18\end{array}$ & $\begin{array}{l}18 \cdot 3 \\
21 \cdot 3\end{array}$ & $\begin{array}{l}22 \cdot 6 \\
26 \cdot 1\end{array}$ & $0 \cdot 38$ & 0.59 \\
\hline \multicolumn{8}{|l|}{ Diplopia: } \\
\hline No & 193 & 55 & 40 & $19 \cdot 9$ & $23 \cdot 4$ & $0 \cdot 85$ & $0 \cdot 54$ \\
\hline $\begin{array}{c}\text { Yes } \\
\text { Vertigo: }\end{array}$ & 58 & 15 & 14 & $22 \cdot 6$ & $22 \cdot 6$ & & \\
\hline \multicolumn{8}{|l|}{ Vertigo: } \\
\hline $\begin{array}{l}\text { No } \\
\text { Yes }\end{array}$ & $\begin{array}{r}203 \\
48\end{array}$ & $\begin{array}{l}59 \\
11\end{array}$ & $\begin{array}{r}45 \\
9\end{array}$ & $\begin{array}{l}19.9 \\
23.7\end{array}$ & $\begin{array}{l}23 \cdot 0 \\
23 \cdot 7\end{array}$ & 0.97 & 0.80 \\
\hline \multicolumn{8}{|l|}{ Ataxia: } \\
\hline No & 159 & 37 & 28 & $21 \cdot 3$ & $26 \cdot 1$ & 0.009 & 0.01 \\
\hline Yes & 92 & 33 & 26 & $18 \cdot 1$ & $19 \cdot 9$ & & \\
\hline \multicolumn{8}{|l|}{ Dysarthria: } \\
\hline No & 235 & 66 & 50 & $20 \cdot 0$ & $23 \cdot 3$ & $0 \cdot 84$ & $0 \cdot 48$ \\
\hline Yes & 16 & 4 & 4 & $15 \cdot 5$ & $15 \cdot 5$ & & \\
\hline \multicolumn{8}{|l|}{ Paraesthesiae: } \\
\hline No & 128 & 49 & 39 & $16 \cdot 5$ & $18 \cdot 0$ & $<0.0001$ & 0.0001 \\
\hline Yes & 123 & 21 & 15 & $29 \cdot 8$ & $30 \cdot 8$ & & \\
\hline \multicolumn{8}{|c|}{ Motor weakness: } \\
\hline No & 121 & 32 & 26 & $22 \cdot 6$ & $24 \cdot 5$ & 0.72 & 0.97 \\
\hline Yes & 130 & 38 & 28 & $18 \cdot 1$ & $21 \cdot 3$ & & \\
\hline \multicolumn{8}{|c|}{ Bladder dysfunction: } \\
\hline No & 206 & 60 & 47 & $19 \cdot 9$ & $23 \cdot 0$ & 0.73 & 0.59 \\
\hline Yes & 45 & 10 & 7 & $21 \cdot 3$ & $24 \cdot 5$ & & \\
\hline
\end{tabular}

*Including definite, probable and possible multiple sclerosis.

tAll causes of death.

$\ddagger$ Multiple sclerosis as underlying and contributing cause of death.

paraesthesiae (table 2). The other clinical manifestations at onset were not significantly related to prognosis. The results were similar in the survival analyses with multiple sclerosis as underlying or contributing cause of death used as end point (tables 1 and 2).

The analyses were repeated with only definite and probable cases included eliminating any bias introduced by including cases with possible multiple sclerosis. Sixty patients were dead out of 185 definite and probable cases. The results in the two analyses were largely comparable, and in the multivariate analyses the possible cases were excluded.

Age at onset, clinical course, and paraesthesiae were significantly related to survival in the multivariate analysis (table 3 ). The longest survival was in patients with young age at onset, remitting course of disease, and paraesthesiae as the initial symptom. The effects of sex and ataxia as initial clinical man- ifestation were not statistically significant in the multivariate analyses. The relations between survival and age at onset, clinical course, and paraesthesiae as initial symptom were similar in the analyses with multiple sclerosis specific death used as endpoint. Survival for the most recent period was, however, slightly poorer, although the low numbers resulted in imprecise estimates (table 3 ).

\section{Discussion}

The present study included all patients with multiple sclerosis who have come to medical attention in the county of Møre and Romsdal, Norway during the 35 year period. A complete and long term follow up was obtained. None of the patients included in this study were treated by immunosuppressive drugs. Therefore, they represent all cases in a defined population and should reflect the

Table 3 Multivariate survival analysis * of multiple sclerosis in More and Romsdal, Norway, 1950-84

\begin{tabular}{|c|c|c|c|c|}
\hline \multirow[b]{2}{*}{ Variable } & \multicolumn{2}{|c|}{ Unadjusted hazard ratios (univariate) } & \multicolumn{2}{|c|}{ Adjusted hazard ratios (multivariate) } \\
\hline & $\begin{array}{l}\text { Total† } \\
(95 \% \mathrm{CI})\end{array}$ & $\begin{array}{l}\text { Multiple sclerosis } \neq \\
(95 \% \text { CI })\end{array}$ & $\begin{array}{l}\text { Total } \\
(95 \% C I)\end{array}$ & $\begin{array}{l}\text { Multiple sclerosis } \neq \\
(95 \% \mathrm{CI})\end{array}$ \\
\hline \multicolumn{5}{|l|}{ Sex: } \\
\hline Men & $1 \cdot 00$ & 1.00 & 1.00 & 1.00 \\
\hline Women & $0.50(0.28-0.87)$ & $0.53(0.29-0.96)$ & $0.61(0.34-1.10)$ & $0.64(0.34-1.19)$ \\
\hline Age at onset (y): & $1.07(1.04-1.10)$ & $1.06(1.03-1.09)$ & $1.06(1.03-1.09)$ & $1.04(1.01-1.08)$ \\
\hline \multicolumn{5}{|l|}{ Year of onset: } \\
\hline $1950-9$ & $1 \cdot 00$ & 1.00 & 1.00 & $1 \cdot 00$ \\
\hline $1960-9$ & $0.90(0.43-1.86)$ & $0.83(0.37-1.86)$ & $1.24(0.59-2.67)$ & $1.09(0.48-2.51)$ \\
\hline $1970-84$ & $1.84(0.79-4.28)$ & $2.29(0.91-5.77)$ & $2 \cdot 10(0 \cdot 89-4 \cdot 93)$ & $2.53(1.00-6.44)$ \\
\hline \multicolumn{5}{|l|}{ Clinical course: } \\
\hline $\begin{array}{l}\text { Remitting + remitting } \\
\text { progressive }\end{array}$ & & & & \\
\hline $\begin{array}{l}\text { progressive } \\
\text { Primary progressive }\end{array}$ & $\begin{array}{l}1.00 \\
3.60(1.87-7 \cdot 11)\end{array}$ & $\begin{array}{l}1.00 \\
3.83 \\
(1.86-7 \cdot 87)\end{array}$ & $\begin{array}{l}1.00 \\
3.44(1.68-7.06)\end{array}$ & $\begin{array}{l}1 \cdot 00 \\
3 \cdot 80 \\
(1 \cdot 78-8 \cdot 1)\end{array}$ \\
\hline \multicolumn{5}{|l|}{ Paraesthesiae: } \\
\hline No & $1 \cdot 00$ & 1.00 & 1.00 & 1.00 \\
\hline Yes & $0.37(0.20-0.67)$ & $0.36(0.19-0.69)$ & $0.46(0.24-0.87)$ & $0.44(0.22-0.86)$ \\
\hline \multicolumn{5}{|l|}{ Ataxia: } \\
\hline No & 1.00 & $1 \cdot 00$ & $1 \cdot 00$ & 1.00 \\
\hline Yes & $1.77(1.01-3.09)$ & $1.98(1.09-3.60)$ & $0.99(0.53-1.86)$ & $1.22(0.63-2.36)$ \\
\hline
\end{tabular}

*Including definite and probable multiple sclerosis.

tAll causes of death.

$\ddagger$ Multiple sclerosis as underlying and contributing cause of death. 
natural history of multiple sclerosis in a high risk area in Scandinavia. Mortality has been recorded until 1 July 1991.

Age at onset of multiple sclerosis was a strong prognostic indicator, with low age at onset of the disease having the most favourable prognosis as shown both in the univariate and the multivariate analyses. The results corroborate several studies as reviewed by Weinshenker and Ebers, ${ }^{19}$ including a recent population based Canadian study. ${ }^{20}$ The duration of multiple sclerosis from onset to death from multiple sclerosis is on average shorter for those with late rather than early onset. Patients with late onset have, however, experienced at least 40 years without symptoms of multiple sclerosis. The survival time is certainly longer for young patients, but the prognosis as judged from the disruption of the normal pattern of life from an early age may indeed be worse. ${ }^{21}$ The shorter survival among patients with a high age at onset may be a reflection of the shorter life expectancy among older patients, independently of the disease; however, in survival analyses including only multiple sclerosis as the underlying cause of death as end point, the statistically significant relation between age at onset and life expectancy remained. Thus the age effect on life expectancy may represent a real biological effect of the disease. In previously published studies $^{1420}$ a significant association between age at onset and entry into moderate or severe residual disability has been found, thus indicating a similar possible biological interplay of age at onset and prognosis. A relative survival analysis that takes into account the mortality in the general population is necessary to consider this issue.

The apparent worsening of the prognosis between 1970 and 1984 is unexpected. The methods of investigation, the record keeping, and the catchment area were identical throughout the study. Death is most often a late event in multiple sclerosis. Due to a short observation time in the most recent cohort, the results may be biased towards the worst cases in the latest period. The diagnostic delay in more benign cases from onset to diagnosis of disease may also contribute to a higher frequency of severe cases. The observed prognostic effect is stronger in the multiple sclerosis specific cohort, and might indicate a more comprehensive classification of deaths from multiple sclerosis in the most recent period. Also, some under-reporting of deaths from multiple sclerosis can be assumed in the previous periods.

An initial remitting course of the disease indicated a favourable prognosis. Thus our study confirms the results from similar investigations. ${ }^{13}$ The advantageous outlook for a longer survival in patients with definite and probable multiple sclerosis with an initial, remitting clinical course remained statistically significant when all causes of death were taken as the end point as well as when multiple sclerosis as underlying or contributing cause of death was the end point. Age at onset is related to course of disease, but age at onset and course of disease showed independent effects on prognosis in the multivariate analysis.

Initial clinical manifestations such as symptoms from the sensory system and the appearance of ataxia showed significance in the univariate analyses independent of the choice of endpoint. Consistent with other reports ${ }^{7} 91122$ paraesthesiae were associated with a favourable prognosis. Ataxia indicated a poorer prognosis, although this was not significant in the multivariate model. The adverse effect of ataxia, interpreted as a combination of dysfunctions in strength and coordination, corroborates earlier reports indicating that pyramidal (motor) and cerebellar findings are generally ominous. ${ }^{7810}$ The presence of multiple symptoms at onset did not reach statistical significance as a prognostic factor in this study.

When death, irrespective of cause, was taken as the end point in the univariate survival analysis, sex was significant indicating that women fared better than men. Similar results were obtained when death with multiple sclerosis as the underlying and contributing cause of death was taken as the end point, although these results were not significant in the multivariate analysis (table 3). These results are consistent with results from previous studies indicating that the survival rate for men with multiple sclerosis is lower than for women, ${ }^{2324}$ although others have failed to show any influence of sex on survival. ${ }^{12} 13$ The life expectancy in general in the Norwegian population shows a lower survival rate for men than women. Our results, showing a difference between men and women, might be a reflection of this fact.

In conclusion, the age at onset of multiple sclerosis and the initial clinical course of disease were the strongest predictors for survival in this study. Paraesthesiae were the only clinical manifestations at onset with a significant effect on duration of survival. Acknowledging the interindividual variability in the natural course of the disease, the prognostic factors identified in this study might be of some help when advising newly diagnosed patients with multiple sclerosis on questions regarding the future.

This study was supported by grants from The Norwegian MS society, the Odd Fellow Order, the Legacy of Ingrid and Fritz Nilsen, and the Norwegian Research Council for Science and the Humanities.

1 Matthews WB. Course and prognosis. In: Matthews WB, ed. McAlpine's multiple sclerosis. London: Churchill ed. McAlpine's multiple scler

2 Müller R. Studies on disseminated sclerosis with special reference to symptomatology, course and prognosis. Acta Medica Scandinavica 1949;suppl 222:1-137.

3 Thygesen P. The course of disseminated sclerosis. A closeup of 105 attacks [dissertation]. Copenhagen Rosenkilde and Bagger, 1953:1-268.

4 Ipsen J. Life expectancy and probable disability in multiple sclerosis. N Engl f Med 1950;243:909-13.

5 Leibowitz U, Kahana E, Alter M. Survival and death in multiple sclerosis. Brain 1969;92:115-30.

6 Hyllested K. Lethality, duration, and mortality of disseminated sclerosis in Denmark. Acta Psychiatrica et Neurologica Scandinavica 1961;36:553-64.

7 Visscher BR, Liu KS, Clark VA, et al. Onset symptoms as predictors of mortality and disability in multiple sclerosis. Acta Neurol Scand 1984;74:321-8.

8 Leibowitz U, Alter M. Clinical factors associated with increased disability in multiple sclerosis. Acta Neurol increased disability in 
9 Poser S, Raun NE, Poser W. Age at onset, initial symptomatology and the course of multiple sclerosis. Acto Neurol Scand 1982;66:355-62.

10 McAlpine D. The benign form of multiple sclerosis. A study based on 241 cases seen within three years of onset and followed up until the tenth year or more of the disease. Brain 1961;84:186-203.

11 Kurtzke JF, Beebe GW, Nagler B, et al. Studies on the natural history of multiple sclerosis VIII. Early prognostic features of the later course of the illness. $\mathcal{F}$ Chron Dis $1977 ; 30: 819-30$.

12 Poser S, Kurtzke JF, Poser W, Schlaf G. Survival in multiple sclerosis. f Clin Epidemiol 1989;42:159-68.

13 Riise T, Grønning $M$, Aarli JA, Nyland $H$, Larsen JP, Edland A. Prognostic factors for life expectancy in multiple sclerosis analysed by Cox-models. $\mathcal{F}$ Clin Epidemiol 1988;41:1031-6.

14 Riise T, Grønning M, Fernández O, et al. Early prognostic factors for disability in multiple sclerosis: a European multicenter study. Acta Neurol Scand 1992;85:212-8.

15 Midgard R, Riise T, Nyland H. Epidemiologic trends in multiple sclerosis in Møre and Romsdal, Norway: a prevalence/incidence study in a stable population. Neurology 1991;41:887-92.

16 Mantel N. Evaluation of survival data and two new rank order statistics arising in its consideration. Cancer Chemotherapy Reports 1966;50:163-70.
17 Cox DR. Regression models and life tables. Fournal of the Royal Statistical Society Series B 1972;34:187-220.

18 Dixon WJ, Brown MB, Engelman L, et al. BMDP Statistical Software. Berkeley: University of California Press, 1985.

19 Weinshenker BG, Ebers GC. The natural history of multiple sclerosis. Can $\mathcal{F}$ Neurol Sci 1987;14:255-61.

20 Weinshenker BG, Rice GPA, Noseworthy JH, Carriere W, Baskerville J, Ebers GC. The natural history of multiple sclerosis: a geographically based study. 3. Multivariate sclerosis: a geographically based study. 3. Multivariate Brain 1991;114:1045-56.

21 Confavreux C, Aimard G, Devic M. Course and prognosis of multiple sclerosis assessed by the computerised data processing of 349 patients. Brain 1980;103: $281-300$

22 Clark VA, Detels R, Visscher BR, Valdiviezo NL, Malmgren RM, Dudley JP. Factors associated with a malignant or benign course of multiple sclerosis. $\mathscr{f} A M A$ 1982;248:856-60.

23 Wynn DR, Rodriguez M, O'Fallon M, Kurland LT. A reappraisal of the epidemiology of multiple sclerosis in Olmsted County, Minnesota. Neurology 1990;40: 780-6.

24 Runmarker B, Andersen O. Prognostic factors in multiple sclerosis incidence cohort with twenty-five years of follow-up. Brain 1993;116:117-34.

\section{Disorders of higher cortical function}

Continued from page 416.

Marcel Proust, 1921, 1922, Remembrance of things past vol 2: cities of the plain

What, then, is a memory which we do not recall? Or, indeed, let us go further. We do not recall our memories of the last thirty years; but we are wholly steeped in them; why then stop short at thirty years, why not extend this previous life back to before our birth? If I do not know a whole section of the memories that are behind me, if they are invisible to me, if I do not have the faculty of calling them to me, how do I know whether in that mass that is unknown to me there may not be some that extend back much further than my human existence? If I can have in me and round me so many memories which I do not remember, this oblivion (a de facto oblivion, at least, since I have not the faculty of seeing anything) may extend over a life which I have lived in the body of another man, even on another planet. A common oblivion obliterates everything. But what, in that case, is the meaning of that immortality of the soul the reality of which the Norwegian philosopher affirmed? The being that I shall be after death has no more reason to remember the man I have been since my birth than the latter to remember what I was before it.

G D PERKIN Regional Neurosciences Centre Charing Cross Hospital, London W6 8RF, UK

1 Perkin GD. Arnold Bennett and medicine: with particular reference to his description of dressing apraxia. $B M \mathcal{F}$ 1981;283:1666-9. 